\title{
SAÚDE E ESPIRITUALIDADE: A VISÃO SISTEMICA DA FAMÍLIA E O PROCESSO DE AMPLIAÇÃO DA CONSCIÊNCIA
}

\author{
Viridiana de Fatima Robaina PACHECO* \\ Marli Olina de SOUZA*
}

RESUMO: Este artigo é resultado de uma análise reflexiva e resultou da necessidade de se construir um pensamento complexo a respeito da família e de se buscar o sentido do conceito de saúde transcendendo a abordagem sistêmica da vida em família, a partir da busca da espiritualidade e do processo de ampliação da consciência (PARODE, 2004) A "Ecologia Profunda" que se remete Fritjof Capra (1998) e a Estética Biocósmica (PARODE, 2004) serão os aportes teóricos para fundamentação desta tese. A ideia a partir de Capra (1998) e com o Enfoque da Ecologia Profunda, poder assumir o Princípio Biocósmico (PARODE, 2004) para o Processo de Ampliação da Consciência, quanto à questão da família e da saúde, ressaltando a importância da espiritualidade como fonte geradora de saúde, a partir da transcendência e naquilo que pode se constituir na imanência do ser.

PALAVRAS-CHAVE: Espiritualidade. Transcendência. Consciência. Saúde. Família.

\footnotetext{
* Doutoranda em Terapia Sistêmica de Família e Terapeuta de Família e de Casal. CAIFCOM - Centro de Ensino, Pesquisa e Atendimento do Indivíduo, Família e Comunidade e Faculdade Evangélica do Meio Norte. Porto Alegre - RS - Brasil. 90550070. Assistente Social. FIERGS - Porto Alegre - RS - Brasil. 91010-971 - viridiana. pacheco@fiergs.org.br, veridiana_pacheco@yahoo.com.br

** Doutoranda em Terapia Famíliar e Coordenadora Pedagógica do Programa de PósGraduação. CAIFCOM - Centro de Ensino, Pesquisa e Atendimento do Indivíduo, Família e Comunidade e Faculdade Evangélica do Meio Norte. Porto Alegre - RS - Brasil. 90550070 - marli@caifcom.com.br
} 


\section{Introduçáo}

Nas últimas três décadas a comunidade científica mundial avança em direção a uma crítica à ciência moderna. A chamada tendência pós-estruturalista problematizada o conhecimento científico, que se orienta pela preocupação de se constituir como sistema formal, a crítica que ao assim fazer, a ciência trata a natureza, a sociedade e a cultura como fenômenos regulares e universais. Surge assim, um novo modelo de interpretaçóes da realidade (citado por PARODE, 2004). As contribuiçóes de Heisenberg (1971) à teoria quântica implicam claramente que o ideal clássico de objetividade científica não pode ser mais sustentado. Assim, a física moderna também esta desafiando o mito de uma ciência livre de valores. Os padrôes que os cientistas observam na natureza estão intimamente relacionados com os padróes de suas mentes, com os seus conceitos, pensamentos e valores. Desta forma minha tese que se constitui entre a ciência e espiritualidade será reforçada, e não invalidados, pelas pesquisas futuras, transpondo uma nova postura cientifica.

Será abordado na questão da visão sistêmica da família visualizamos os paralelos entre a saúde e espiritualidade, estáo aparecendo não apenas na física, mas também na biologia, na psicologia e em outras ciências. Embora este paralelo entre a ciência e espiritualidade na atualidade tem gerado transformaçóes e sendo discutidas por físicos e filósofos ao longo das últimas décadas, propomos a discutir os conceitos da física moderna o qual surpreendem seus paralelos face às ideias expressas nas filosofias religiosas do extremo oriente. Embora esses paralelos até o presente momento não tenham sido extensivamente discutidos, nem isso escaparam à observação de alguns dos grandes físicos do século XX no momento que entraram em contato com a cultura oriental, da Índia, China e Japáo, como segue nas três citaçóes seguintes, segundo Chopra, (2006, p.213):

A grande contribuição cientifica em termos da Física Teórica que nos chegou do Japão na última guerra pode ser um indício de certa relação entre as idéias filosóficas presente na tradiçẫo do Extremo Oriente e a substância filosófica da teoria quântica. (Werner Heisenberg)

As noçôes gerais acerca da compreensão humana [...], ilustradas pelas descobertas na Física atômica, estão longe de constituir algo inteiramente desconhecido, inédito e novo. Essas noções possuem uma história em nossa própria cultura, desfrutando de uma posição mais destacada e central no pensamento budista ou hindu. Aquilo com que nos deparemos não passa de uma exemplificação, de um enco- 
rajamento e de um refinamento da velha sabedoria. (Julius Robert Oppenheimer)

Se buscarmos um paralelo para a liçáo da teoria atômica [...] (devemos nos voltar) para aqueles tipos problemas epistemológicos com os quais já se defrontaram, no passado, pensadores como Buda e LaoTsé em sua tentativa de harmonizar nossa direção como expectadores e atores no grande drama da existência. (Niels Bohr).

A exploração do mundo atômico e subatômico, no século XX, tem revelado uma limitação insuspeita das idéias clássicas, levando, por conseguinte, a uma revisão radical de inúmeros de nossos conceitos básicos.

Assim, investigamos o que é saúde na visão cartesiana tradicionalista e como ainda se faz presente na ciência médica hoje o tratamento do paciente como partes, cada especialista vê e trata como se fosse uma peça de automóvel que não esta funcionando bem, é como se fosse possível trocar a peça e toda engrenagem ficasse perfeita, será mesmo que é possível estarmos bem ou saudável como se o corpo fosse apenas o que comanda tudo, onde esta a mente separada deste corpo?

Conforme Capra (1998, p.37), "A nova concepção do universo não foi facilmente aceita, pelos cientistas do começo do século desencadeando modelos estruturais fragmentados da saúde integral do Ser". Desta forma a ênfase dada ao pensamento racional em nossa cultura está sincronizada no célebre enunciado de Descartes, equiparando sua identidade com a mente racional e não com o organismo total. Veremos que os efeitos dessa divisão entre corpo e mente são sentidos em toda nossa cultura. A divisão entre o espirito e a matéria levou a concepção do universo como um sistema mecânico que consiste em objetos separados. Sendo assim, tal concepção mecanicista no mundo ainda está em base da maioria de nossas ciências e continua e exercer uma enorme influência em muitos aspectos de nossa vida.

Saúde ou doença não são estados ou condiçôes estáveis, mas sim conceitos vitais, sujeitos a constante avaliação e mudança. Num passado ainda recente a doença era frequentemente definida como "ausência de saúde", sendo a saúde definida como "ausência de doença", definiçóes que não eram esclarecedoras. Esta visão reducionista levou a investigadores e os profissionais da saúde a descurar os componentes emocionais e sociais da saúde ou doença (BOLANDER, 1998).

Em consequência da divisão cartesiana, indivíduos, na maioria, têm consciência de si mesmos como egos isolados existindo "dentro" de seus 
corpos. A mente foi separada do corpo, recebendo a inútil tarefa de controlá-lo, causando um conflito aparente entre a vontade consciente e os instintos involuntários. Capra (1982) reforça esta teoria quando diz que cada indivíduo foi separado nesta lógica e dividido num grande número de compartimentos isolados de acordo com as atividades que exercem seu talento, seus sentimentos, suas crenças, etc.

Dessa forma, a teoria sistêmica constitui um dos principais arcabouços teóricos para a compreensão da família como um sistema complexo (DESSEN; BRAZ, 2005). Assim, adotando uma visão sistêmica da família, com a complexidade, a instabilidade e a intersubjetividade que essa visão envolve (VASCONCELLOS, 2003), esta pesquisa, pretende-se aprofundar o tema da saúde da família numa visão sistêmica.

\section{A visão sistêmica da família}

Atualmente, mesmo em um processo de mudança contínua da estrutura, das funçóes e do papel social da família, pode ser encontrada uma série de concepçóes da instituição familiar, dentre as quais se destacam aquelas que a veem como uma instituição básica, natural e indispensável da sociedade humana, expressão substancial do tecido social e o espaço ideal para o cuidado dos filhos e o desenvolvimento humano (BELLO, 1984).

Nesse processo, merecem destaque Watzlawick, Beavin e Jackson (apud LUIS OTERO, 1983) ao afirmarem que um organismo vivo ou um corpo social não se constitui em um conglomerado de partes elementares ou de processos elementares, pois existe uma hierarquia integrada de sub-totalidades semiautônomas, sendo que as unidades funcionais em todos os níveis são bifrontes, atuam como um todo e como partes. Embasados em tal princípio, consideram a família como um conjunto de indivíduos que funciona através das relaçóes que se estabelecem entre eles, cujos atributos afetam diretamente ao meio social em que estão inseridos e este, em modificação permanentemente, atua na estrutura e na organização da família e, consequentemente, na conduta de seus membros.

Assim sendo, a visão sistêmica ou ecológica da família estrutura-se como o mais novo paradigma científico, alicerçando o atual "referencial teórico e prático de compreensão do fenômeno família” (COSTA, 1992). Partindo dessa premissa, a família pode ser vista como parte (subsistema) do sistema social, tendo em vista suas permanentes inter-relaçôes com os demais subsistemas sociais (laser, escola, religião, cultura, política e outros). 
Além disso, ao constituir-se em um sistema, pode ser vista como um todo, trabalhando, permanentemente, para manter a homeostase interna (auto regulação) de seus subsistemas (membros), constituída por regras, fronteiras, hierarquia, poder, papéis, comunicação, segredos, mitos e uma estrutura inconsciente, que "compóem a dinâmica relacional entre seus membros" (COSTA, 1992). Fica, então, mais clara a percepção, na prática, do que Cerqueira e Kompinsky (1991) apontam como patologia familiar ou de um de seus membros. As inter-relaçóes entre os componentes da família, desta em relação ao restante da sociedade e de como a família reage aos fatores circunstanciais da vida têm como base "a troca ininterrupta de vivências entre os indivíduos e seu ambiente (família e sociedade)", mantendo-se em equilíbrio passível de flutuaçôes.

Por outro lado, os mesmos autores, alegam que o inverso é da mesma forma real, haja vista o processo evolutivo de a sociedade dar-se como reflexo das mudanças internas ocorridas na família. Reforça, ainda, Gilliéron (1982) tal aspecto, ao afirmar que uma mudança no contexto em que vive um indivíduo, traz a ele novas informaçóes, que reagirá para restabelecer o equilíbrio original ou estabelecer um novo equilíbrio. Assim, segundo Fausto Neto (1982), não se pode perder de vista algumas "situaçôes familiares", tais como a forma de união entre seus elementos; a definição das tarefas específicas de cada um; o planejamento de sua estrutura; a definição da autoridade; a organização hierárquica interna, mesmo em situaçóes adversas como a necessidade de contribuição financeira dos filhos e outras. Dessa forma, qualquer abordagem familiar deverá contemplar suas relaçóes internas, entre seus integrantes, e as externas, entre ela e os demais subsistemas sociais. Igualmente, ao ser abordado um indivíduo, jamais deve ser esquecida a sua realidade subjetiva, bem como, a sua realidade social, visando, assim, à superação da dicotomia artificial e irreal entre o individual e o social.

A família é um sistema em constante transformação, experimentando pressôes em direção à mudança tanto internamente, através dos papéis dos membros individuais satisfazendo as exigências de seu ciclo de vida, como externamente, através das exigências sociais e das experiências diversas, proporcionando crescimento ou não no ciclo de vida desta família. Desta forma, entendemos que a expansão dos pensamentos e emoçôes bem orientados sob o comando de uma consciência espiritualizada, se torna um hábito de alta eficácia para o bom estado de saúde, enquanto os pensamentos depressivos agridem o próprio sistema imunológico (GROISMAN, 2012). Tais pressões, de origem física, mental ou social, com suas repercussōes na família e, individualmente, em seus membros, 
configuram-se como sendo as crises familiares que poderiam ocorrer frente a um determinado acontecimento, na dependência da interaçáo de diversos fatores internos e externos à família.

Os sistemas vivos são sistemas abertos tanto do ponto de vista material quanto do energético. Eles utilizam constantemente matéria e energia para produzir, reparar e perpetuar a si mesmos. Devido às condiçôes do ambiente que o cerca, os sistemas promovem a criaçáo de novas estruturas e novas formas de organização que os levam ao desenvolvimento e à evolução (CAPRA, 2002). A vida não evolui em progressão, mas num movimento pendular, movimentos opostos, às vezes aparentemente contraditórios de avanço e retrocesso (WHITMONT, 1989). Isso é resultado da interação energética que mobiliza o universo sendo responsável pelo comportamento dos seus elementos. Verifica-se que a evolução biológica não trilha um caminho linear, e que o retrocesso faz parte do processo. O material genético herdado dos pais representa o holograma contendo informaçóes do conjunto de estruturas do ser, sendo certo que isto limita as possibilidades de expressão do sistema, que só poderá se exibir num complexo semelhante ao parental (CARILLO JÚNIOR, 2008).

Apesar de a família ser o ponto de confluência das realidades vividas por seus integrantes, ela náo deve ser vista como o somatório de comportamentos individuais, devendo ser percebida como um processo integrado em permanente evolução de cada um de seus membros e sempre em relação com o outro. Deve-se, utilizando a observação de Neder (1994), valorizar os núcleos familiares enquanto lócus de produção de identidade social, com vistas à formaçáo de uma cidadania ativa, desprendendo-se de um enfoque moralista, embasado em preocupaçôes limitadas ao comportamento e à atitude.

\section{Doença}

Em culturas pré-históricas de todo o mundo, a origem da doença e o processo de cura estavam associados a forças pertencentes ao mundo dos espíritos, e uma grande variedade de rituais e práticas de cura foram desenvolvidos para tratar as doenças em conformidade da época. O chamado Pai da Medicina ocidental identificou a saúde como fruto do equilíbrio dos humores, sendo, por oposição, a doença, resultante do desequilíbrio dos mesmos. Alguns praticantes da medicina contemporâneos ou sucessores de Hipócrates interpretaram a teoria humoral de maneira mais estrita (abrindo exceção apenas para os ferimentos), enquanto outros 
admitiam a intromissão de agentes externos, como os venenos, na determinação das doenças.

Segundo Simão e Saldanha (2012) toda pessoa enfrenta situaçôes de estresse durante toda a vida, desde o nascimento até a morte, as quais podem trazer implicaçóes diversas para a saúde física e mental. A nossa capacidade de resiliência tem a função de nos ajudar a reformar nossos comportamentos, permitindo renovar nossas atitudes diante das adversidades, buscando vencer cada desafio e aprender com cada lição.

[...] o padrão de organização de um sistema vivo como a configuraçấo das relaçóes entre os componentes do sistema, configuração essa que determina as características essenciais do sistema; a estrutura do sistema como a incorporação material desse padrão de organização; e o processo vital como o processo contínuo dessa incorporação. (CAPRA, 2002, p.61).

Segundo Fritjof Capra (1975) especifica que a saúde e a doença estáo relacionadas no tipo de hábitos da vida cotidiana, na teoria mais importante no Corpus Hipocrático, o livro sobre Ares, Águas e Lugares, representa o que poderíamos chamar agora de um tratado sobre ecologia humana, isto é, atitudes sustentáveis para vida humana e meio ambiente. Mostra com grande detalhe como o bem-estar dos indivíduos é influenciado por fatores ambientais - a qualidade do ar, da água e da comida, a topografia e os hábitos de vida em geral, requer um estado de equilíbrio em meio às influências do ambiente, o modo de vida, e os vários componentes da natureza humana.

Relacionando a ideia do autor que toda doença provoca tensão familiar, tende a se elevar com discussóes e brigas, dadas as contínuas frustraçôes, reprovaçôes e culpas que muitas vezes não sabendo gerir os conflitos familiares e dividir tarefas acaba provocando stress elevados. De forma geral, quanto mais próximo o grau de parentesco maior será o impacto e a tendência dos familiares modificarem suas vidas em funçáo de assistir ao doente, portanto, os membros da família cedem às exigências do doente, deixam de usufruir de suas vidas e/ou evitam auxiliar nos cuidados necessários. O autor Fritjof Capra (1975, p.101) exemplifica a espiritualidade a alma faz parte do corpo em que:

"A sede da alma", onde todas as impressóes dos sentidos se encontram. O corpo humano era uma expressáo exterior e visível da alma; modelada pelo seu espírito". Veremos que essa visão da alma e do 
espírito, não mutilada pela cisão mente-corpo que René Descartes introduziria nos século XVII, é perfeitamente consistente com a ideia de "mente corporificada" na ciência cognitiva de hoje.

Os familiares e membro com doenças crônica através da espiritualidade possui relação estreita na melhora da qualidade de vida de pacientes com doenças crônicas procuram na Espiritualidade principalmente suporte, sentido, explicação e tentativa de cura, Cada vez mais pesquisas sugerem que a religiosidade e a espiritualidade sejam fatores importantes para as pessoas que sofrem ou estáo doentes. Para aquelas pessoas com crença espiritual tendem a demonstrar positividade na adversidade, como enfrentamento da doença e tratamento da saúde para o avanço na construção de instrumentos de medida sobre religiosidade e espiritualidade. Portanto a espiritualidade favorece a qualidade de vida, dignidade e melhora do bem-estar nos doentes crônicos podendo ajudar na dor espiritual.

Corpo e alma formavam um todo indivisível, Fritjof Capra (1975) explica que na autoria sáo instrumentos orgânicos desse corpo ela não pode nem realizar nem sentir nada, a unidade essencial de corpo e alma surge bem no início da vida e dissolve-se com a extinção de ambos na morte. É completamente consistente com a ciência cognitiva moderna, na qual viemos a compreender a relação entre mente e corpo como uma relação entre processo (cognitivo) e estrutura (viva), que representam dois aspectos complementares do fenômeno da vida. "No mundo da medicina vibracional, a doença é causada não apenas por germes, substâncias químicas e traumas físicos, mas também por disfunçóes crônicas dos padróes de energia emocional e pelos maus hábitos de relacionamento da pessoa consigo mesma e com os outros. $\mathrm{O}$ caminho vibracional não usa bisturis e medicamentos de laboratório para tratar as doenças, mas sim diferentes formas de energia para produzir transformaçóes curativas na mente, no corpo e no espírito do doente, hoje através da medicina psicossomática, sabemos que as emoçóes desorganizadas, como cólera e o desespero, anulam as defesas favorecendo campo orgânico para o surgimento das doenças." (DURGANTE, 2012, p.149).

Para analisarmos o binômio saúde-doença no contexto da espiritualidade, precisamos partir da visão trina do ser humana. Enquanto o materialismo se restringe a uma abordagem superficial, olhando apenas para o corpo e considerando a mente como substrato do cérebro, o olhar espiritualista transcende a matéria e vai buscar entender o processo de adoecer e de curar na relação do corpo, onde as causas não se restringem à superfície 
do corpo, para buscá-las na profundidade da alma. "Uma alma é nossa identidade interior, nossa razão de ser" (RABINO, 1995, p.18) assim, alma significa a vida de uma pessoa, alma e espirito são as mesmas coisas. A energia salutar da vida humana. $O$ corpo precisa do espirito para funcionar, A alma da música é a visáo do compositor que energiza e dá vida às notas tocadas em uma composição musical.

Portanto, para Hahnemann (1995), o ser humano é constituído de corpo (matéria), espírito e força vital. Essa força vital é que vai organizar e dar vida a matéria, sustentando o seu funcionamento e possibilitando a saúde. $\mathrm{O}$ organismo é um instrumental material da vida, onde o corpo e a força vital formam uma unidade inseparável. Ele prossegue afirmando: O organismo material, destituído da força vital, não é capaz de nenhuma sensação, nenhuma atividade, nenhuma autoconservação; é somente o ser imaterial e no estado mórbido (o princípio vital a força vital), que lhe dá toda sensação e estimula suas funções Vitais. A doença seria consequência da perturbação desta força vital de natureza espiritual.

De acordo com Alberto de Paula Barreto (2012), a doença orgânica e psicológica se manifesta quando as mensagens sutis não são decifradas, os traumatismos não são levados a sério, resta ao corpo um último recurso, as doenças. Conforme o autor as doenças, ao mesmo tempo em que instigam a receber mensagens do que não esta bem no ser permite ao ser a dar vazão a energias tensionais armazenadas, obrigando o sujeito a olhar a bússola interior para vislumbrar o futuro que o espera.

Desta forma, as doenças também falam da condição física e mental e convida o ser humano a uma reflexão sobre seus limites, dificuldades de aceitar mudanças e de admitir limitaçóes. As doenças enfraquecem ou revigoram a imunidade interior. Ainda Barreto (2012), reforça que: "Quanto mais grave e profunda for à doença e mais antiga é a tensão interior a ser eliminada. O sintoma da doença é, portanto a expressão visível de um processo invisível."

Byington (apud MACIEL, 2000, p.52) alerta:

Diante de certos sintomas como cefaleia, palpitação, parestesias ou cólicas verticais, o médico costuma pesquisar componentes orgânicos dos sintomas, sem levar em conta qualquer componente simbólico. [...] quando não encontra nenhum componente orgânico que justifique a doença, receitas "tranquilizantes", que alteram quimicamente a vivencia norma do símbolo, dificultando sua expressão e estruturação. 
A concepção sistêmica do universo como um sistema vivo possibilita-nos a compreender os sintomas das doenças como sendo formas físicas, materiais de expressão dos conflitos ou desequilíbrios, e que, por meio de uma linguagem simbólica, informam onde se situam os problemas do ser. Corintha Maciel (2000, p.43) é enfática: “[...] a 'chave' para compreender a doença e a cura é aprender a 'traduzir' a fala do sintoma, reconhecendo-a como um símbolo que se precipitou no corpo físico.” Descodificar essa mensagem possibilita ao homem ressignificar, reorientar seu comportamento, sua vida. Negar esse aspecto, esse sinal de alerta, é privar o ser humano de transformar a doença numa oportunidade para rever valores, repensar relacionamentos e postura na família, no meio, no mundo. A interpretação de um sintoma, não nega a contribuição da medicina biológica que explica, mecânica e eficazmente, qualquer sintoma, mas sim oportuniza agregar valores ao ato de cura. Desta forma, Adalberto de Paula Barreto (2012, p.202) conclui que:

Toda doença manifesta-se por sintomas que atingem nosso corpo físico e precisa ser pensada e tratada também na sua multiplicidade de possibilidades. É claro que muitas vezes os remédios alopáticos são necessários e imprescindíveis, mas precisamos ir além da explicação mecânica, bioquímica para extrair mensagens inconscientes, que são verdadeiras bússolas para o caminhar humano.

A medicina atualmente ainda permanece no paradigma materialista. A doença é entendida como um fenômeno puramente natural. No entanto, à medida que a própria ciência avança em busca da confirmação de seus pressupostos avança o entendimento no meio científico da questão mente e corpo. A exposição resulta em doença somente quando o indivíduo exposto se encontra num estado receptivo, e isso depende das condiçôes climáticas, da fadiga, do estresse e de uma série de outras circunstâncias que influenciam a resistência da pessoa à infecção (CAPRA, 1982). Novamente nos deparamos com a afirmação de que para se tratar uma doença de forma completa não adianta apenas uma intervenção física ou bioquímica. Podemos sugerir então que, se tudo o que existe vibra em uma frequência e nós também somos feitos de energia, quando entramos em ressonância com alguma forma vibracional que altere a funçáo normal de qualquer desses corpos sutis, adoecemos. As doenças vão dos corpos sutis para o físico e os sintomas são apenas uma manifestaçáo do problema interno. Um dos maiores avanços da física foi o Teorema da Interconectividade de Bell, que diz que nós estamos em conectividade 
com todos os pontos do Universo. Influenciamos tudo e sofremos influência de tudo. Logo, se entrarmos em ressonância com o que está nos fazendo mal, desta forma podemos adoecer.

\section{Visão mecanicista da saúde}

Capra (1982) para entendimento de mecanicista para Descartes, o universo material era uma máquina, nada além de uma máquina. Não havia propósito, vida ou espiritualidade na matéria. A natureza funcionava de acordo com leis mecânicas, e tudo no mundo material podia ser explicado em função da organização e do movimento de suas partes. Esse quadro mecânico da natureza tornou-se o paradigma dominante da ciência no período que se seguiu a Descartes. Passou a orientar a observação científica e a formulação de todas as teorias dos fenômenos naturais, até que a física do século XX ocasionou uma mudança radical. Toda a elaboração da ciência mecanicista nos séculos XVII, XVIII e XIX, incluindo a grande síntese de Newton.

Segundo Queiroz (1986) explica que no século XVII, Descartes estabeleceu os métodos para se pensar o corpo humano como máquina, não concordava com Galileu que tinha mostrado o método científico que era capaz de providenciar uma interpretação mecânica do mundo físico. Desta forma Descartes não via razão porque os mesmos princípios não podiam ser estendidos ao mundo das criaturas vivas, criou a dicotomia entre mente (uma concepção divina, fora do alcance da ciência) e corpo (um organismo imperfeito que obedece a leis mecânicas), onde ficaram definidas as diferenças de corpo e mecânica. Ao longo da História, diversos modelos de saúde têm ocupado, sucessivamente e, consoante o evoluir das civilizaçóes, lugar de destaque na prática da Medicina e, de certa forma, também no papel crescente da Psicologia nesse domínio. Três dos mais relevantes e que tiveram maior impacto são o Modelo Biomédico, o Modelo Biopsicossocial e o Modelo Holísta.

\section{- Modelo biomédico}

No formato mecanicista na saúde especificamente no modelo biomédico refletindo no referencial técnico instrumental das biociências, exclui o contexto psicossocial dos significados aos quais uma compreensão plena e adequada nas capacidades relacionais permitem o estabelecimento de um vinculo adequado e uma comunicação efetiva. Dessa forma, a inspiração na visão mecanicista do ser humano, considera que saúde é mera 
ausência de doença e que, como numa máquina, se uma das peças se "avaria”, há que se centrar na sua reparação. O paradigma hegemônico na saúde (mecanicista-newtoniano) originou o modelo biomédico, caracterizado pela separação corpo-mente, saúde-doença, parte-todo. Tal abordagem fortalece um modelo assistencial centrado no hospital, dependente de especialidades médicas, que valoriza o uso de tecnologias pesadas, resultando em elevados custos econômicos com pouco impacto na produção de saúde e formação humanística (BRASIL, 2010).

As características fundamentais do paradigma mecanicista são: Mecanicismo - concepção do universo, da natureza, do homem, como se fossem máquinas, governadas por leis matemáticas exatas; Empirismo apenas o conhecimento construído a partir de fatos concretos, passíveis de serem percebidos pelos sentidos e passíveis também de serem medidos e quantificados, teria valor científico; Determinismo - uma vez conhecendo-se as leis que causam os fenômenos seria possível determinar com precisão a sua evolução; Fragmentaçáo - a decomposição do objeto de estudo em suas partes componentes, perdendo-se, muitas vezes, a visáo do todo; Reducionismo - a perda da visão sistêmica e complexa dos processos; Dicotomia - a separaçáo entre mente e corpo, sujeito e objeto, ser humano e natureza, razão e intuição.

$\mathrm{Na}$ visão de Queiroz (1986), o paradigma como "mecanicista" por pressupor que, da mesma forma que qualquer objeto natural no mundo do homem, como a saúde e a doença podem ser explicada exclusivamente pela interação mecânica, das diferentes partes do organismo humano. Com as grandes descobertas a doença aparece como um distúrbio de um dos componentes da máquina humana passível de ser reparado pela intervençáo de uma medicina que detivesse o conhecimento das leis que operam essa máquina. $\mathrm{O}$ corpo humano perdia assim seu caráter divino, intocável.

A mente humana era um centro de inteligência e razáo, projetada para analisar e compreender. Foucault (1995) nas ciências humanas não é uma análise do que o homem é por natureza; são antes uma análise que se estende entre o que o homem é em sua positividade (ser que vive, trabalha, fala) e o que permite a esse mesmo ser saber (ou buscar o saber) o que é a vida para ele próprio, em que consistem a essência do trabalho e suas leis.

\section{- Modelo biopsicossocial}

Neste modelo proporciona uma visão integral do ser que compreende as dimensóes, em que o Biopsicossocial trata-se de uma perspectiva que 
dá importância já não só aos aspectos biológicos da saúde humana, mas também a aspectos psicológicos e sociais. De acordo com Straub (2005), o modelo biopsicossocial, explica que os comportamentos se caracterizam por processos biológicos, psicológicos e sociais. Esse modelo enfatiza a influência mútua entre esses aspectos no desenvolvimento humano, fundamentando-se na teoria sistêmica do comportamento, que compreende que o corpo é formado por sistemas em interação, como o endócrino, o cardiovascular, o nervoso e o imunológico, que interagem com os aspectos psicossociais.

\section{- Modelo holístico}

A mudança de concepçáo mecanicista para a holística, deriva da palavra grega Holos que significa julgar uma coisa pela inter-relação funcional de todas as partes. Com a evolução de uma visão dualista de saúde e doença para a visão da saúde como um contínuo, o passo seguinte em termos de modelos é dado pelo Modelo Holista, dotado de uma visão do indivíduo como um todo e da saúde como subjetiva. De acordo com este modelo, o indivíduo tem um papel ativo na sua saúde, cabendo ao técnico de saúde auxiliá-lo no processo de tratamento e levando a cabo iniciativas de educação para saúde. Para o autor Morin (2005, p.26):

O holismo só abrange visão parcial, unidimensional, simplificadora do todo. Faz da ideia de totalidade uma ideia à qual se reduzem as outras ideias sistêmicas, quando deveria ser uma ideia confluente. $\mathrm{O}$ holismo depende, portanto, do paradigma de simplificaçâo (ou redução do complexo a um conceito-chave, a uma categoria-chave).

O paradigma holístico completo oferece um modelo dinâmico de ver e considerar tudo como um todo. Ao aplicar princípios de totalidade na própria vida diária, a pessoa desenvolve uma perspectiva que aumenta a sensibilidade interior para todo o teu ser FÍSICO - EMOCIONAL MENTAL - ESPIRITUAL. Da mesma forma, no processo de mudar a visão de si num conceito de totalidade, podendo ver a si mesmo com clareza nas relaçóes externas com outras pessoas ou com o meio ambiente. Teixeira (1996) confirma que a saúde para ser holística precisa ser estudada como um grande sistema, como um fenômeno multidimensional, que envolve aspectos físicos, psicológicos, sociais e culturais, todos interdependentes e não arrumados numa sequência de passos e medidas isoladas para atender cada uma das dimensôes apontadas na vida das pessoas. 
Segundo Capra (1975) compara a visão xamanística com a medicina ocidental.

Capra (1975) ainda avisa que as comparaçóes entre sistemas médicos de diferentes culturas devem ser feitas com todo o cuidado. Qualquer sistema de assistência à saúde, incluindo a medicina ocidental moderna, é um produto de sua história e existe dentro de certo contexto ambiental e cultural, o sistema de assistência à saúde também muda, adaptando-se às sucessivas situações e sendo modificado por novas influências econômicas, filosóficas e religiosas. Este modelo holístico afirmaria que mais de uma força tem uma importância no resultado, sempre voltado a busca do equilíbrio, várias abordagens foram propostas para compreender o processo saúde-doença. Capra (1975) intensifica que saúde e doença é o estado psicossocial do ser humano em que se estabelece no singular espiritual.

$\mathrm{Na}$ influência da visão holística enfoca sempre no ser humano, trata-se no desenvolvimento humano inserido num contexto biopsicossocial como ser singular que traz consigo uma história de vida, empregado de valores culturais mudando do ambiente do próprio cotidiano para regras institucionais. Contudo, vivemos tempos inundados de informaçóes de comunicaçáo e absolutamente desnutridos de vozes filosóficos, com este cenário surge o aumento de estresse, descontentamento de usuários e profissionais de saúde de resgatar os valores subjetivos que foram perdidos com os avanços da ciência, não se trata de abandonar as inovaçôes tecnológicas e cientificas, sim, agregar valores humanos ás relaçôes que ocorrem nas instituiçốes de educação e saúde, buscando articulação baseadas nos princípios éticos, sendo assim, respeitando e valorizando todos os seres humanos envolvidos nesta teia.

\section{Corpo}

A construção do corpo pode ser visto como um processo histórico, e sendo construído historicamente podemos localizar bem o significado ou a percepçáo do que vem a ser corpo ao longo da historia. "[...] O corpo humano é socialmente concebido e a análise da representação social do corpo oferece umas das numerosas vias de acesso à estrutura de uma sociedade particular." (RODRIGUES, 1979, p.44). Na visão da medicina ocidental, quando um corpo apresenta problemas funcionais à causa é atribuída a defeitos estruturais produzidos por desequilíbrios químicos. Embora a homeostase dependa de uma ligaçáo com a energia situada a um nível mais profundo isso não é levado em conta. O ser humano é visto como uma máquina biológica. 
O corpo físico na visão da física quântica é constituído de matéria com propriedades de partículas e ondulatórias simultaneamente. A propriedade ondulatória da matéria irá conferir característica de frequência tanto ao corpo físico quanto ao elétrico. A teoria energética equipara o homem ao elétron de um átomo, pois ocupa diferentes modos vibracionais que são chamados de órbita de saúde e doença e somente uma dose de energia sutil de frequência apropriada fará com que esse corpo passe para uma nova órbita assim como os elétrons que ocupam casulos de energia conhecidos como orbitais. Cada orbital apresenta características de energia e frequência, dependendo do tipo de átomo. A fim de que o elétron passe para o próximo orbital superior é preciso transmitir-lhe energia de uma determinada frequência, somente um quantum de energia exata fará com que o elétron salte para um orbital superior. A este salto dá-se o nome de princípio da ressonância.

A medicina ocidental ou medicina Newtoniana trabalha com componentes químicos e estruturais do corpo físico, a natureza se encontra num nível espaço/tempo quadridimensional em contra partida a medicina vibracional ou Einsteiniana trabalha com energias que sofrem influência da atividade mental e emocional do homem. A essa energia ou força vital, dá-se o nome de espírito. É uma energia sutil que anima todos os seres vivos e influencia na saúde e na doença.

O corpo físico é composto de arranjos com partículas atômicas e subatômicas, sendo assim, as moléculas são formadas por partículas menores chamadas átomos, que reduzidas a partículas menores são os elétrons, nêutrons e prótons. Toda matéria é constituída por esse arranjo de partículas atômicas e subatômicas tal quais os elétrons que apresentam em sua composição dois elementos: ondas e partículas. Essa dualidade é um reflexo da relação matéria/energia estudada por Einstein e sintetizada como $\mathrm{E}=\mathrm{mc}^{2}$. Com isso pode-se converter matéria em energia e vice-versa.

O fóton é uma partícula mediadora da força eletromagnética e também representa o quantum da radiação eletromagnética, que inclui a luz. Possui Spin igual a um. Atua tanto como partícula (quando registrado por um mecanismo sensível a luz) quanto como onda (quando passa através de uma lente ótica). De acordo com a dualidade partícula / onda da física quântica é natural que um fóton apresente ambos os aspectos de acordo com as circunstâncias em que se encontra. A luz é formada por um grande número de fótons, quanto maior o número de fótons maior a intensidade ou brilho.

Quando o fóton de alta energia transforma-se em duas partículas reduz a velocidade, passando a ter propriedades atribuíveis à matéria 
(massa) e ainda conservar algumas das propriedades ondulatórias. A partir disto afirma-se que toda matéria é luz congelada. E é constituída por campos de energia complexos. Como seres multidimensionais que somos e não apenas carne, ossos, células e proteínas, somos constituídos da mesma substância básica de que é feito o Universo, luz congelada. A dualidade onda/partícula da matéria mostra que a estrutura física humana possui propriedades que possibilitam a construção de um novo modelo de corpo físico. Isto ocorre no nível das partículas, pois, toda matéria é energia. Então se o homem é matéria ele também é energia com isso pode-se afirmar que o homem é um ser de energia multidimensional.

\section{Considerações finais}

O desenvolvimento do ser pela busca da plenitude constatou-se que a busca da espiritualidade pela pratica da transcendência, ou seja, a busca pela evolução oportuniza ao ser perceber-se como ser intuitivo e enxergar o meio, o oculto e conhecer-se. Desta forma, conforme Nilton Bonder, (1995, p.13) perceber a manifestar as intervençôes no intuitivo oculto:

[...] Poder manipular e controlar certas áreas do conhecimento sutil, poder transmitir a sensação de um sonho. A Intuição se manifesta vez por outra maneira bastante específica no mundo aparente. Nestas ocasióes, podemos pressentir algo que permite fazer uso deste conhecimento vazado aparente. O pressentimento é a tomada de forma de algo que parece romper com a lógica objetiva de causa e efeito. Em realidade, esta conexão é sentida porque o que identifica certa forma não são outras formas, mas um meio do qual o intuidor resgatou esta determinada forma. Para que possamos conceber qualquer possibilidade de intervenção voluntária no oculto, devemos definir melhor a natureza das relaçóes entre o parente e o oculto.

Desta forma como pode o homem intervir no meio, não intervindo, permitindo que primeiro se apresentem repostas, para só então resgatar suas perguntas. Se o ser em evolução, no seu processo de busca de alto conhecimento e expansão da consciência aceita as respostas intuitivas e as permite rondar por sobre seu coração, em algum momento, é possível que a resposta exata resgate alguma destas respostas rondantes. Possibilitar pela proposta de trabalho focada no que acredito ressonar o eco em todo universo através da saúde e espiritualidade transcenden- 
do a visão sistêmica da família a partir do processo de ampliação da consciência. A busca constante da evolução humana conduz a família, o meio, a uma prática vindoura de saúde integral. Percebe-se que o trabalho com a saúde desenvolvido em todos estes anos me permitiu inserir a construção para educação integral do Ser e nele seu núcleo familiar. A olhar a família com o que já existia ali e estava adormecido, o amor incondicional e que pelo seu processo de evolução consensual permite-lhe transformar seu meio.

A Filosofia contemporânea inclina-se a conceber o homem como um ser pluriversal na representação de sua situação e face da realidade opera-se, uma inversão na direção dos vetores que circunscrevem o lugar ontológico do sujeito: para o homem universal esses vetores convergem, segundo a metafísica da reflexáo sujeito-realidade; do homem pluriversal esses vetores irradiam, segundo a modalidade da abertura do sujeito às várias regióes do ser que se oferecem ao seu conhecimento e à sua ação. Desta forma a nova ciência e nossa proposta é transcender o visível e entender deixar fluir, a tua dor em passagem de luz. Este amor quântico na família, percepção da forma cósmica. De acordo com o Stephen, então eu arrisco ir mais longe: entender o universo é compreender o amor. Compreender o amor é vivê-lo. O amor de verdade é, portanto, Quântico e apenas ele é capaz de atribuir sentido à Humanidade.

Ao ser humano, nấo bastam mais as satisfaçóes que a vida material pode oportunizar. Queremos felicidade plena, Iluminação. Não nascemos para a tristeza e não nos conformamos sequer com as dores da alma. Somos pessoas talhadas para um mundo novo e estamos vivendo um momento em que podemos querer bem mais. Por isso, em Inteligência Quântica e as Múltiplas Personalidades do Bem, trabalharemos com a energia da alma, do sopro de vida, do sentir, das vibraçôes, das emoçóes boas, do otimismo, da convicção de que o melhor sempre acontece, da bondade, das virtudes, dos dons, das qualidades, da preservação do que é bom, do que inflama o sentir, da relação positiva entre a mente e a esfera emocional, do amparo à vida, da vida pulsando, da inteligência, do raciocínio e da coerência, condiçôes que asseguram saúde física, emocional e mental aos seres humanos. Penetrando nesse universo em que a magia é possível, você desenhará sua personalidade do bem, acendendo luzes intensas e coloridas em seu corpo quântico e contribuindo para que nosso planeta evolua de forma que possamos experimentar uma onda de boa vontade envolvendo todos os seres. (MENEZES, 2006, p.10). 


\section{Agradecimento}

A Mestra Marli amiga de autora e desta caminhada evolutiva, agradeço a você por ser como é, pelo carinho, paciência e competência, pelo incentivo da produção que originou neste trabalho. Agradeço a nossa convivência que espero que exista por muito tempo, além deste plano, é, para mim, um maravilhoso exercício da felicidade.

Marli, Os Sábios compreenderão. Definitivamente, que Há uma estrutura energética organizando e sustentando o aparelho biológico. Esse mecanismo, quando desalinhado, propicia os desequilíbrios orgânicos. A ciência do amanhã levará em conta a mente como grande senhora e essência do corpo e o mundo sofrerá bela revolução: a da fé raciocinada.

\section{HEALTH AND SPIRITUALITY: THE FAMILY SYSTEMIC VISION AND THE PROCESS OF AWARENESS EXPANSION}

ABSTRACT: This article is the result of a reflective analysis and resulted in the need to build a complex thinking about the family and to seek the meaning of the concept of health transcends the systemic approach of family life, from the search of spirituality and process magnification of consciousness (PARODE, 2004). The "Deep Ecology" which refers Fritjof Capra (1998) and Biocósmica Aesthetics (PARODE, 2004) will be the theoretical contributions to substantiate this thesis. The idea from Capra (1998) and the focus of Deep Ecology, power take Biocósmico Principle (PARODE, 2004) for the enlargement process of consciousness, on the issue of family and health, stressing the importance of spirituality as source of health from the transcendence and what can be the immanence of being.

KEYWORDS: Spirituality. Transcendence. Awareness. Health. Family.

\section{REFERÊNCIAS}

BRASIL. Ministério da Saúde. Secretaria de Ciência, Tecnologia e Insumos Estratégicos. Como elaborar projetos de pesquisa para o PPSUS: guia. Brasília, 2010.

BARRETO, A. de P. Terapia comunitária passo a passo. 3.ed. Fortaleza: Gráfica LCR, 2012. 
BELLO, J. Interaccion entre la familia y el proceso de desarrollo. Montevideo: Instituto Interamericano del Niño, 1984. (Boletin julio/ diciembre).

BOLANDER, V. B. Enfermagem fundamental: abordagem psicofisiológica. Lisboa: Lusodidacta, 1998.

BONDER, N. O segredo judaico de resolução de problemas. São Paulo: Rocco, 1995.

CAPRA, F. As conexóes ocultas: ciência para uma vida sustentável. São Paulo: Cultrix, 2002.

CAPRA, F. A teia da vida. 3.ed. São Paulo: Cultrix, 1998.

CAPRA, F. O ponto de mutaçáo. São Paulo: Cultrix, 1982.

CAPRA, F. Tao da Física. São Paulo: Cultrix, 1975.

CARILLO JUNIOR, R. O milagre da imperfeição: vida, saúde e doença numa visão sistêmica. São Paulo: Cultrix, 2008.

CERQUEIRA, R. T. B. de; KOMPINSKY, E. Adolescência: uma crise familiar. Jornal Brasileiro de Psiquiatria, Rio de Janeiro, v.40, n.9, p.471-477, 1991.

CHOPRA, D. A cura quântica. São Paulo: Best Sellers, 2006.

COSTA, I. I. Sobre a necessidade de uma visão global e integrada de consideraçáo e intervençáo na realidade familiar. In: BRASIL. Ministério do Bem-Estar Social. Centro Brasileiro para a Infância e Adolescência. Família: ponto de chegada ou de partida. Rio de Janeiro: CBIA, 1992. (Cadernos CBIA, n.4).

DESSEN, M. A.; BRAZ, M. P. A família e suas inter-relações com o desenvolvimento humano. In: DESSEN, M. A.; COSTA JUNIOR, A. L. (Org.). A ciência do desenvolvimento humano: tendências atuais e perspectivas futuras. Porto Alegre: ARTMED, 2005. p.113-131.

DURGANTE, C. E. A. Conectando ciência, saúde e espiritualidade. Porto Alegre: Francisco Spinelli, 2012.

FAUSTO NETO, A. M. Q. Família operária - reproduçáo da força de trabalho. Rio de Janeiro: Vozes, 1982. 
FOUCAULT, M. A arqueologia do saber. Tradução de Luiz Felipe Baeta Neves. 4.ed. Rio de Janeiro: Forense Universitária, 1995.

GILLIÉRON, E. O clínico geral e a família: uma abordagem sistêmica. Diálogo Médico, São Paulo, v.8, n.2, p.18-27, 1982.

GROISMAN, M. Família é Deus: descubra como a família define quem você é. Rio de Janeiro: Núcleo de Pesquisas, 2012.

HAHNEMANN, S. Organon der Heilkunst: Organon da arte de curar. 6.ed. Ribeirão Preto: Museu de Homeopatia Abrahão Brickmann, 1995.

HEISENBERG, W. Physics and beyond: encounters and conversations. Londres: Allen \& Unwin, 1971.

LUIS OTERO, R. Ecologia social: factores estructurales y psicosociales del sistema familiar. Revista Costarricense de Ciencias Médicas, Costa Rica, v.4, n.2.p.55-64, 1983.

MACIEL, C. Mitodrama: o universo mítico e seu poder de cura. São Paulo: Ágora, 2000.

MENEZES, J. Inteligência quântica: aplicaçôes da teoria quântica na transformação humana. Porto Alegre: Besouro Box, 2006.

MORIN, E. Ciência com consciência. 8.ed. Rio de Janeiro: Bertrand Brasil, 2005.

NEDER, G. Ajustando o foco das lentes: um novo olhar sobre a organização das famílias no Brasil. In: KALOUSTIAN, S. M. (Org.). Família brasileira: a base de tudo. São Paulo: Cortez; Brasília: UNICEF, 1994. p.26-46.

PARODE, V. P. Estética vibracional: um processo multidimensional de ampliação da consciência. Porto Alegre: Alcance, 2004.

QUEIROZ, M. de S. O paradigma mecanicista da medicina, ocidental moderna: uma perspectiva antropológica. Revista de Saúde Pública, São Paulo, v.20, p.309-17, 1986.

RABINO, S. J. Rumo a uma vida significativa a sabedoria do Rebe. São Paulo: Domínio Público, 1995.

RODRIGUES, J. C. Tabu do corpo. Rio de Janeiro: Achiame, 1979. 
SIMÃO, M. J. P.; SALDANHA, V. Resiliência e psicologia transpessoal: fortalecimento de valores, açóes e espiritualidade. Revista Mundo da Saúde, São Paulo, v.36, n.2, p.291-302, 2012.

STRAUB, R. Introduçáo à Psicologia da saúde. Porto Alegre: ARTMED, 2005.

TEIXEIRA, C. M. Educação de pais gestantes. Porto Alegre: Ed. Agel, 1996.

VASCONCELLOS, M. J. E. Pensamento sistêmico: o novo paradigma da ciência. 2.ed. Campinas: Papirus, 2003.

WHITMONT, E. C. Psique e substância. São Paulo: Summus, 1989. 
